\title{
Relationships among scores on the Stanford-Binet IV, Peabody Picture Vocabulary Test-Revised, and Columbia Mental Maturity Scale
}

\author{
HOWARD CARVAJAL, KATHLEEN HARDY, KATHY HARMON, \\ TODD A. SELLERS, and COOPER B. HOLMES \\ Emporia State University, Emporia, Kansas \\ (Stephen F. Davis, Sponsor)
}

\begin{abstract}
This study investigated the correlations among the Stanford-Binet Intelligence Scale (4th Edition), the Peabody Picture Vocabulary Test-Revised, and the Columbia Mental Maturity Scale. A kindergarten class of 21 children (10 boys, 11 girls) took each test, and the intercorrelations of the total scores and the correlation between the Binet IV Vocabulary subtest and the Peabody were calculated. Only the relations between Binet IV and Peabody and between Binet IV Vocabulary and Peabody were found to be statistically reliable.
\end{abstract}

In 1986 the fourth edition of the Stanford-Binet Intelligence Scale (Binet IV) (Thorndike, Hagen, \& Sattler, 1986) was published. Numerous important changes were made in the development and organization of Binet IV. A three-level hierarchical model was utilized in the conceptualization of Binet IV. Mental age and IQ were discarded, and standard age scores are now reported for the composite, the four areas (Verbal Reasoning, Quantitative Reasoning, Abstract/Visual Reasoning, and ShortTerm Memory), and the 15 subtests.

Two of the more popular screening tests of intelligence in use today are the Peabody Picture Vocabulary TestRevised (PPVT-R) and the Columbia Mental Maturity Scale (CMMS). These tests are useful because they save time and provide reliable and valid data about a client. Lubin, Larsen, and Matarazzo (1984) stated that PPVT-R was tied for seventh place in frequency of mention of use and had a weighted score rank of 10 of evaluation instruments of all types in 1982 in a survey of psychiatric hospitals, community mental health centers, schools for the retarded, counseling centers, and Veterans Administration hospitals. Salvia and Ysseldyke (1985) stated that CMMS is a well-standardized and technically adequate test, which was designed for children who have difficulty responding verbally. Kaufman (1978) stated that CMMS "is undoubtedly the best brief instrument (verbal or nonverbal) available, and it ranks as one of the finest for assessing preschool children" (p. 301).

Screening tests are used because they provide meaningful data quickly, accurately, and conveniently; they can be used to identify those individuals who need to be evaluated in depth. Screening tests must give results similar to the Wechsler series or to the Stanford-Binet; conse-

Please address correspondence to Howard Carvajal, Division of Psychology and Special Education, Emporia State University, 1200 Commercial, Emporia, KS 66801-5087. quently, the value of screening tests of intelligence is determined primarily by their relationships to the Wechsler or the Binet. Therefore, information concerning the relationships between the new Binet IV, PPVT-R, and CMMS will be of interest to psychologists, particularly those whose practices include evaluation of young children.

Because the Binet IV Technical Manual does not provide correlative data between the Binet IV and other screening devices, the present study was designed to yield preliminary data on this issue. The Binet IV Vocabulary subtest has both picture and oral vocabulary items; knowledge of its relationship to PPVT-R (a measure of receptive vocabulary) may be meaningful to psychologists. Specifically, answers to the following questions were sought: (1) What are the relationships between Binet IV, PPVT-R, and CMMS? (2) What is the relationship between PPVT-R and CMMS ? (3) What is the relationship between PPVT-R and the Vocabulary subtest of Binet IV?

\section{METHOD}

\section{Subjects}

A kindergarten class of 21 children (10 boys and 11 girls), from a Midwest community of about 27,000, was given all three tests. At the time of testing, the children ranged in age from 5 years, 1 month to 6 years, 11 months. The children would be described as middle class; among the boys was 1 black and among the girls 1 Hispanic.

\section{Testing Instruments}

The complete battery of Binet IV was administered. For kindergartenaged children, the complete battery consists of eight subtests: Vocabulary, Bead Memory, Quantitative, Memory for Sentences, Pattern Analysis, Comprehension, Absurdities, and Copying. The mean and the standard deviation of the composite standard age scores are 100 and 16 , respectively, whereas the mean and standard deviation of the subtest standard age scores are 50 and 8 , respectively.

Each child was given the CMMS and Form L of the PPVT-R. These tests have means of $\mathbf{1 0 0}$ for their total scores and standard deviations of 16 and 15 , respectively. 
Table 1

Descriptive Statistics

\begin{tabular}{|c|c|c|c|c|c|c|}
\hline \multirow[b]{2}{*}{ Test } & \multicolumn{2}{|c|}{ All Subjects } & \multicolumn{2}{|c|}{ Male Subjects } & \multicolumn{2}{|c|}{ Female Subjects } \\
\hline & Mean & $S D$ & Mean & $S D$ & Mean & $S D$ \\
\hline \multicolumn{7}{|l|}{ Binet IV } \\
\hline Composite SAS* & 113.4 & 11.8 & 115.1 & 10.5 & 111.8 & 13.1 \\
\hline Vocabulary SAS* & 57.5 & 5.1 & 57.8 & 6.5 & 57.2 & 3.5 \\
\hline Peabody Picture Vocabulary Test-Revised SSE $\dagger$ & 112.5 & 12.3 & 112.7 & 12.8 & 112.3 & 12.6 \\
\hline Columbia Mental Maturity Scale ADS $\ddagger$ & 110.3 & 12.8 & 108.0 & 11.6 & 112.4 & 14.0 \\
\hline
\end{tabular}

*SAS $=$ standard age scores. $\quad$ †SSE $=$ standard score equivalent. $\quad$ †DS $=$ age deviation score.

\section{Procedure}

Testing was conducted between September 25, 1986 and December 15, 1986. No attempt was made to counterbalance the administration of the tests. One examiner administered Binet IV, another CMMS, and another PPVT-R. The testing was conducted between the hours of 1:30 and 3:30 p.m. The examinations were given in a room that had been specifically designed and equipped for testing.

\section{RESULTS}

The male children scored higher on PPVT-R, Binet IV, and the Binet IV Vocabulary subtest. The females' mean score was higher on CMMS. However, no statistically significant differences occurred between male and female means on any of the tests. There were no statistically significant differences found between the means of PPVT-R, CMMS, and Binet IV. The descriptive statistics are summarized in Table 1.

The Pearson product-moment coefficient of correlation was used to determine the relationships of the tests and the relationship of PPVT-R with the Binet IV Vocabulary subtest. Table 2 provides a summary of these correlations. The correlations between Binet IV and PPVT-R and between PPVT-R and the Binet IV Vocabulary subtest were statistically significant; however, the correlations between Binet IV and CMMS as well as between PPVT-R and CMMS were not statistically significant.

\section{DISCUSSION}

The correlation between Binet IV and PPVT-R was .560; this correlation is close to the relationship of Binet IV and PPVT-R $(r=.601)$ determined for a class of third graders (Carvajal, McVey, Sellers, Weyand, \& McKnab, 1987). Data of the current study also were consistent with the median value of .62 derived from 72 studies of the relationship of the old Stanford-Binet and PPVT (Dunn \& Dunn, 1981). The .560 correlation found in this study supports the use of PPVT-R in those situations where a screening test may be appropriate.

The PPVT-R and Binet IV Vocabulary test had a correlation of .603; this may imply that these two measures tap similar skills, although the

Table 2

Correlations

\begin{tabular}{lll}
\hline Test & & $r$ \\
\hline Binet IV Composite SAS & - PPVT-R SSE & $.560^{*}$ \\
Binet IV Composite SAS & - CMMS ADS & .400 \\
Binet IV Vocabulary SAS & - PPVT-R SSE & $603^{*}$ \\
PPVT-R SSE & - CMMS ADS & .222 \\
\hline
\end{tabular}

Note-SAS $=$ standard age scores. PPVT-R $=$ Peabody Picture Vocabulary Test-Revised. SSE = standard score equivalent. CMMS = Columbia Mental Maturity Scale. ADS $=$ age deviation score. ${ }^{*} p<.01$ correlation is not high enough to warrant the substitution of one for the other. At the 5- and 6-year-old levels of the Binet IV Vocabulary test, the child begins with picture vocabulary and progresses to those items that require definitions. PPVT-R does not require that any words be defined; instead, it is a measure of receptive vocabulary. Carvajal et al. (1987) found a slightly lower relationship $(r=.533)$ with third graders; this difference may have occurred because kindergartners encounter some picture vocabulary on Binet IV Vocabulary, whereas third graders ordinarily do not.

Binet IV and CMMS had a correlation of only .400; this correlation was considerably lower than the relationship described in the CMMS manual between the 1960 Stanford-Binet and CMMS $(r=.67)$ (Burgemeister, Blum, \& Lorge, 1972). In the Carvajal et al. (1987) study of third graders, the correlation was .477. CMMS requires that the child make perceptual and visual discriminations, and psychologists often use CMMS when testing special populations. On the basis of its rather low correlation and the lack of statistical significance in the current study, CMMS should be used sparingly, if at all, as an alternative for Binet IV.

The correlation of PPVT-R and CMMS was quite low $(r=.222)$. This is consistent with data from third graders (Carvajal et al., 1987). Because these tests appear to tap different skills and abilities, they should not be used interchangeably.

The children in this study had higher means and smaller standard deviations than those employed in the standardization of the various tests. Such homogeneity may have reduced the size of the correlations. In a homogeneous group, small fluctuations in scores may impact quite negatively on the size of a correlation coefficient.

This study indicates that PPVT-R should be the instrument of choice, instead of Binet IV, when a screening test is to be used. The use of CMMS should be limited to those children whose vocabulary skills are deficient and underdeveloped.

\section{REFERENCES}

BurgemeISTER, B., Blum, L., \& LORGE, I. (1972). Guide for administering and interpreting the Columbia Mental Maturity Scale (3rd ed.). New York: Harcourt Brace Jovanovich.

Carvajal, H., McVey, S., Sellers, T., Weyand, K., \& McKnab, P. (1987). Relationships between scores on the general purpose abbreviated battery of Stanford-Binet IV, Peabody Picture Vocabulary Test-Revised, Columbia Mental Maturity Scale, and GoodenoughHarris Drawing Test. The Psychological Record, 37, 127-130.

Dunn, L., \& DunN, L. (1981). Manual for the Peabody Picture Vocabulary Test-Revised. Circle Pines, MN: American Guidance Service. Kaufman, A. (1978). Review of the Columbia Mental Maturity Scale. In O. Buros (Ed.), The eighth mental measurements yearbook. Highland Park, NJ: Gryphon.

Lubin, B., Larsen, R., \& Matarazzo, J. (1984). Patterns of psychological test usage in the United States: 1935-1982. American Psychologist, 39, 451-4.54.

SALVIA, J., \& YSSELDYKE, J. (1985). Assessment in special and remedial education (3rd ed.). Boston, MA: Houghton Mifflin.

Thorndike, R., HAgen, E., \& SATtLer, J. (1986). Guide for administering and scoring the Stanford-Binet Intelligence Scale (4th ed.). Chicago, IL: Riverside.

(Manuscript received February 11, 1987.) 